\title{
FILOSOFIA E O EXERCÍCIO DO PENSAMENTO CONCEITUAL NA EDUCAÇÃO BÁSICA
}

Sílvio Gallo*

\section{RESUMO}

O presente artigo tem por objetivo discutir as implicações para o ensino de filosofia quando a tomamos como pensamento conceitual. Apresenta-se a idéia de que há ao menos três registros para o pensamento: imagético ou figurativo; lógico; e conceitual, cada qual com suas características próprias, relacionando-os com a idéia de Pierre Lévy de três pólos do espírito, cada qual com suas ferramentas de pensamento específicas (oralidade; escrita; informática). Trabalha-se a noção de filosofia como criação de conceitos, a partir do proposto por Deleuze e Guattari, articulando essa noção com outras obras de Deleuze, especialmente Diferença e Repetição. Por fim, ao discutir a cultura do pensamento na sala de aula, defende a necessidade de um deslocamento do eixo educativo do ensino para o aprendizado, como forma de possibilitar aos estudantes a experiência do pensamento conceitual.

Palavras-chave: Ensino de Filosofia. Conceito. Pensamento Conceitual. Experiência. Aprendizado.

\begin{abstract}
This article has for objective to argue the implications for the teaching philosophy when we understand philosophy as conceptual thought. It is presented the idea that there are, at least,

Professor da Faculdade de Educação da Universidade Estadual de Campinas (UNICAMP) e Pesquisador do CNPq. Coordenador do DiS - Grupo de Estudos e Pesquisas Diferenças e Subjetividades em Educação - FE-Unicamp. E-mail: gallo@unicamp.br
\end{abstract}


three registers for the thought: figurative; logical; and conceptual, each one with its proper characteristics, relating them with the Pierre Lévy's idea of three poles of the mind, each one with its specific tools of thought (orality; writing; information technologies). This paper presents, also, the notion of philosophy as creation of concepts, proposed by Deleuze and Guattari, articulating this notion with other works of Deleuze, especially Difference and Repetition. Finally, when arguing the culture of the thought in the classroom, defends the necessity of a displacement of the educative axle from teaching to learning, as form to make possible to the students the experience of the conceptual thought.

Keywords: Teaching philosophy. Concept. Conceptual Thinking. Experience. Learning.

\section{Três registros do pensamento}

A ponte não é de concreto, não é de ferro

Não é de cimento

A ponte é até onde vai o meu pensamento

A ponte não é para ir nem pra voltar

A ponte é somente pra atravessar

Caminhar sobre as águas desse momento

(Lenine - A Ponte - CD O Ano em que faremos contato, 1997)

"A ponte é até onde vai meu pensamento". A cultura do pensamento é a construção de pontes, de conexões, que não são feitas de concreto, ferro ou cimento, mas conexões elétricas e efêmeras como as sinapses, sempre em transição. Pensar é conectar. Pensar é construir pontes. Para utilizar uma expressão de Deleuze e Guattari, pensar por conceitos é uma atitude sintagmática, de estabelecer relações e conexões. ${ }^{1}$

1 Ver O que é a filosofia?, obra em que definem o conceito como sintagmático. Voltarei a este tema adiante.

Educ. e Filos., Uberlândia, v. 22, n. 44, p. 55-78, jul./dez. 2008. 
Quando investigamos a cultura do pensamento na escola, na sala de aula, devemos distinguir entre as modalidades de pensamento. De forma simples e direta, penso que podemos falar em três modalidades básicas: a. o pensamento por figuras ou imagens; b. o pensamento por palavras; $c$. o pensamento por conceitos.

O pensamento por imagens está presente já nos primórdios da humanidade. A observação espacial, necessária para o exercício da caça e das demais atividades de sobrevivência, nos fez desenvolver uma modalidade de pensamento que articula as imagens e nos permite fazer medidas, tirar conclusões. Hoje, praticamos essa forma de pensamento por imagens fazendo cálculos espaço-temporais de forma "automática" ou mesmo "inconsciente". A utilizamos quando caminhamos pela rua ou dentro de casa, quando dirigimos um automóvel, quando estamos em uma loja ou em um supermercado, por exemplo.

Sabemos do impacto que teve a invenção da linguagem oral e depois da linguagem escrita para a humanidade. Não é por acaso que um filósofo francês contemporâneo fala da oralidade e da escrita como duas das principais tecnologias de inteligência inventadas pela humanidade. ${ }^{2} \mathrm{O}$ uso da palavra como ferramenta, para além da comunicação, significou uma revolução na nossa forma de pensar. Passamos a pensar também por palavras, mais do que por imagens, o que possibilitou que se processasse o pensamento com mais rapidez, com maior rigor. A este tipo de pensamento, os antigos gregos chamaram logos, significando, a um só tempo, palavra e razão. Com isto, estabeleceram uma espécie de vínculo indissociável entre pensamento e palavra, obscurecendo o pensamento por imagens.

Em um primeiro momento, o próprio pensamento por imagens se vale da palavra: é a construção das metáforas, das parábolas como forma de pensar e de fazer pensar o outro. No âmbito da

2 Ver Pierre Lévy, As Tecnologias da Inteligência - o futuro do pensamento na era da informática. Rio de Janeiro: Ed. 34, 1993. 
cultura da oralidade, sabemos da importância que tiveram e têm ainda as metáforas e palavras. Apenas dois exemplos: o pensamento mitológico antigo, sobretudo dos gregos, é um pensamento por figuras; o pensamento religioso, também. Destaque-se o uso das parábolas nos textos religiosos, compilados de antigas tradições orais, e também os discursos (ou sermões) dos sacerdotes, sempre carregados de parábolas e metáforas.

A invenção da escrita gerou um novo impacto no pensamento, e a palavra tomou o lugar de importância da figura como ferramenta do pensamento. Quando um tal processo já estava consolidado, o filósofo Aristóteles definiu o ser humano como um zoon logon echon, isto é, como o "animal portador da palavra", como ser de linguagem, ou ainda, como ficaria universalmente conhecido, um "animal racional". O logos grego, que traduzimos tanto por palavra quanto por razão, tinha esse duplo significado, como afirmei anteriormente.

O pensamento por palavras é, de longe, o mais utilizado pelos seres humanos. E o próprio pensamento por figura acabou por ser "traduzido" em palavras, embora procedam de forma distinta. Quando exercitamos o pensamento em nosso cotidiano, quando usamos o "bom senso" ou "senso comum", estamos pensando por palavras. Quando raciocinamos, quando "dialogamos" conosco mesmos, estamos pensando com palavras. Quando fazemos ciência, estamos fazendo uso das palavras como ferramenta de pensamento.

Mas os gregos antigos criaram, porém, uma terceira modalidade de pensamento: o pensamento por conceitos. E fizeram isso ao criar uma nova "disciplina" do pensamento, à qual deram o nome de Filosofia. Deleuze e Guattari (1992, p. 115-116) afirmam que "os filósofos são estrangeiros, mas a filosofia é grega", uma vez que os primeiros filósofos são estes seres estranhos que vêm das bordas do mundo grego, das colônias jônicas, nas margens da Ásia, das colônias itálicas, da ilha da Sicília, e que encontram na Grécia, especialmente em Atenas, uma pátria.

Segundo eles, são três as condições que encontramos na antiga Grécia que possibilitaram a emergência da filosofia: uma

Educ. e Filos., Uberlândia, v. 22, n. 44, p. 55-78, jul./dez. 2008.

58 
sociabilidade que se coloca como meio de imanência; um cultivo da amizade que é ao mesmo tempo um gosto pela rivalidade, pela disputa: o amigo é o bom oponente; ${ }^{3}$ e, por fim, um gosto pela opinião e pela conversação. É por conta da conjugação destes três fatores no mesmo espaço e tempo que a filosofia floresce e viceja. E o mais importante: a filosofia inventa, na pura imanência, o pensamento por conceitos, à distinção do pensamento por figura dos antigos sábios e religiosos, com seu apelo pela transcendência.

É uma sabedoria, ou uma religião, pouco importa. É somente deste ponto de vista que se pode aproximar os hexagramas chineses, as mandalas hindus, as sefirót judias, os "imaginais" islâmicos, os ícones cristãos: pensar por figuras [...] Numa palavra, a figura é essencialmente paradigmática, projetiva, hierárquica, referencial (as artes e as ciências também erigem poderosas figuras, mas o que as distingue de toda religião, não é aspirar à semelhança proibida, é emancipar tal ou tal nível para dele fazer novos planos do pensamento sobre os quais as referências e projeções, como veremos, mudam de natureza). (Deleuze e Guattari, 1992, p. 118)

À distinção destas quatro características da figura, o conceito é sintagmático, conectivo, vicinal e consistente. O que significa que ele opera no registro da imanência, por conexões e por vizinhança, fora de qualquer sistema de referência. Voltaremos adiante ao conceito e a suas características. Por ora, a intenção era apenas a de mostrar que o pensamento não é único, nem unitário, nem homogêneo. Para além da hegemonia de um pensamento por palavras, encontramos também um pensamento por figuras ou imagens e um pensamento por conceitos. Seus diferentes modos estão presentes, misturam-se, uns atravessam os outros. Mas é possível distingui-los.

3 O agonismo grego, o gosto pela disputa na batalha nas eras heróicas que se transmuta pelo gosto pelo debate, pela disputa verbal na Grécia clássica, é também destacado por Giorgio Colli como sendo uma das condições da filosofia em O Nascimento da Filosofia. 


\section{Pierre Lévy e os três pólos do espírito}

A discussão em torno dos três registros do pensamento encontra um elemento importante no conceito de tecnologias da inteligência, desenvolvido por Lévy. Podemos falar em tecnologias do pensamento e em como o pensamento se mobiliza e se transforma em torno de cada uma destas ferramentas tecnológicas.

A necessidade de dominar a natureza pelo conhecimento, possibilitando a sobrevivência num mundo muitas vezes hostil, fez com que os seres humanos produzissem e continuem produzindo tecnologias de conhecimento, isto é, aparatos, mecanismos, que permitam que examine os aspectos da realidade que deseje transformar em objeto de estudo. Sem tais tecnologias, não seria possível o conhecimento ou, pelo menos, seu desenvolvimento dar-se-ia de forma muito mais lenta. Tais tecnologias são produzidas historicamente, repito, de acordo com as possibilidades e problemas de cada momento. Por outro lado, o uso de tais tecnologias influi sobre o próprio saber que se produz, definindo-o num campo próprio a tal tecnologia, do qual nem sempre é possível escapar. Num texto instigante, Pierre Lévy coloca a questão de forma bastante clara:

As tecnologias intelectuais desempenham um papel fundamental nos processos cognitivos, mesmo nos mais cotidianos; para perceber isto, basta pensar no lugar ocupado pela escrita nas sociedades desenvolvidas contemporâneas. Estas tecnologias estruturam profundamente nosso uso das faculdades de percepção, de manipulação e de imaginação. Por exemplo: nossa percepção da cidade onde vivemos muda dependendo se costumamos ou não consultar seus mapas. Muitas vezes, os métodos para resolver certos problemas são incorporados nos sistemas de representações que a cultura nos oferece, como é o caso, por exemplo, na notação matemática e nos mapas geográficos. (Lévy, 1993, p. 160)

Lévy delimita o que denomina de os "três tempos do espírito", os três grandes momentos da história do conhecimento humano

Educ. e Filos., Uberlândia, v. 22, n. 44, p. 55-78, jul./dez. 2008.

60 
marcados por suas tecnologias específicas: o pólo da oralidade primária, característico do momento civilizatório em que a humanidade ainda não dominava as tecnologias da escrita e o conhecimento era transmitido através da palavra, momento este dominado por um conhecimento que costumamos chamar de mitológico; o pólo da escrita, com todo o impacto que essa tecnologia gerou sobre o saber humano, resultando na constituição da Filosofia e da(s) Ciência(s); e, por fim, o pólo mediáticoinformático, no qual adentramos a partir da segunda metade do século vinte e que já nos permite vislumbrar assombrosas possibilidades para o conhecimento, dada a variedade e velocidade que possibilita.

Cada um destes três pólos apresenta características próprias e diferentes impactos sobre o conhecimento, sobre as tecnologias que utiliza e sobre os saberes que pode desencadear. Limitando-nos aos aspectos que dizem respeito a nosso tema, podemos afirmar que a oralidade engendra um saber do tipo narrativo, baseado na ritualidade; a escrita, por sua vez, apresenta um saber teórico baseado na interpretação, enquanto que a informática possibilita um saber operacional baseado na simulação (através de modelos ou previsões). ${ }^{4}$

Para Lévy, há uma historicidade nestes três pólos do espírito. Podemos mesmo falar em uma espécie de evolução, na medida em que a tecnologia da escrita permitiu avanços significativos sobre os saberes produzidos com a tecnologia da oralidade e que a tecnologia informática, por sua vez, induziria avanços em relação aos saberes produzidos com a tecnologia da escrita. Mas quero aqui caminhar numa direção diferente: interessa-me fazer uma analogia dos três pólos do espírito com as três modalidades de pensamento. Não numa dimensão histórica e evolutiva, mas como três realidades distintas, embora contemporâneas e coexistentes.

Fazendo uma aproximação com o quadro proposto por Lévy, podemos relacionar o pensamento por imagens com a oralidade,

${ }^{4}$ Cf. LÉVY, op. cit., quadro recapitulativo à página 127. 
produzindo narrativas, e o pensamento por palavras com a escrita, produzindo teorias. O pensamento por conceitos é que escaparia deste quadro, uma vez que identificá-lo com a escrita seria relacioná-lo também com a teoria e com sua característica paradigmática que, como já vimos, o conceito não apresenta. Tampouco poderíamos aproximá-lo da informática, uma vez que o pensamento por conceitos foi inventado na antiguidade, muito distante destas tecnologias que apenas nas últimas cinco décadas estão sendo desenvolvidas. O pensamento por conceitos é esta diferença em relação ao pensamento projetivo que colonizou nossas mentes com a oralidade e a escrita. Tampouco a tecnologia informática abre espaço para o pensamento por conceitos, mas ele permanece, mesmo que à margem dos modos hegemônicos de pensar.

Se para Lévy o aparecimento de uma nova tecnologia da inteligência não elimina a(s) anterior(es), é bem verdade que acaba ocorrendo um processo de hegemonização desta nova tecnologia. Sua análise é clara em mostrar como a tecnologia da escrita se sobrepõe à tecnologia da oralidade, em como a invenção da imprensa dá um novo impulso e muito mais poder à tecnologia escrita, e daí seu otimismo em relação às novas tecnologias de inteligência que foram e estão sendo inventadas pela informática, sua crença de que o pensamento e seu exercício estão sendo e serão profundamente transformados. Assim, se há uma convivência entre as diferentes tecnologias, tal convivência dá-se baixo uma hierarquia, havendo sempre uma tecnologia dominante. Isto implica em uma espécie de evolução, na noção de uma história evolutiva.

De modo quase análogo, podemos afirmar que as três modalidades do pensamento (imagético ou figurativo; lógico; conceitual) coexistem desde a antiguidade. O pensamento conceitual foi o último dos três a emergir, mas nem por isto é superior aos demais; vivem, os três, sob a hegemonia do pensamento lógico, que muito bem soube utilizar-se da tecnologia da escrita para construir seu império e colonizar nossas mentes, produzindo maravilhas como todo o saber científico moderno. No

Educ. e Filos., Uberlândia, v. 22, n. 44, p. 55-78, jul./dez. 2008.

62 
entanto, vaza de seus limites o pensamento por figuras, em nossas atividades cotidianas, bem como nas atividades e discursos religiosos, por exemplo; e vaza de seus limites o pensamento por conceitos, exercício crítico e criativo da filosofia. Se o pensamento imagético já teve seu momento de hegemonia, ao pensamento por conceitos isto parece não interessar. Ele se coloca para além de qualquer processo hegemônico.

\section{A filosofia como exercício do pensamento conceitual}

No quadro do que foi apresentado até aqui, podemos definir a filosofia como a atividade de criar conceitos. ${ }^{5}$ Isso quer dizer que, no exercício da filosofia, não pensamos por palavras? Exatamente. $\mathrm{Na}$ filosofia, usamos também as palavras como ferramentas, mas elas são apenas uma forma de expressar os conceitos, assim como elas também expressam as figuras e imagens, através de metáforas e parábolas. O essencial do pensamento filosófico é o trato com os conceitos.

Já Kant havia definido o pensamento como "o conhecimento por conceitos"; no entanto, para ele o conceito seria uma forma de "representação universal", enquanto que a intuição seria uma forma de "representação singular" ${ }^{6}$ Acompanhemos sua definição de conceito:

Todos os conhecimentos, isto é, todas as representações conscientemente referidas a um objeto são, ou intuições ou conceitos. A intuição é uma representação singular; o conceito, uma representação universal ou representação refletida.

O conhecimento por conceitos chama-se pensar. (Kant, 2003, p. 181)

5 Ver Gilles Deleuze e Félix Guattari, O que é a filosofia?. Rio de Janeiro: Ed. 34, 1992.

6 Ver Kant, Manual dos cursos de Lógica Geral. 2a ed. Campinas/Uberlândia: Ed. Unicamp/Edufu, 2003. 
Mais adiante, lemos sobre como se formam os conceitos, segundo o filósofo, a partir dos atos lógicos da comparação, da reflexão e da abstração:

Os atos lógicos do intelecto, pelos quais os conceitos se produzem segundo sua forma, são:

1) a comparação, isto é, o cotejo das representações entre elas, na sua relação com a unidade da consciência;

2) a reflexão, isto é, a consideração reflexiva sobre como representações diversas podem ser concebidas numa consciência; e, finalmente,

3) a abstração ou a separação de tudo o mais em que as representações dadas se distinguem. (Kant, 2003, p. 187)

Na visão deste filósofo, quando intuímos não pensamos. Pensamos apenas quando organizamos uma representação universal das coisas, isto é, quando articulamos conceitos. Ainda para ele, o conceito é uma espécie de definição. Por exemplo, o conceito de mesa é algo que diz universalmente o ser mesa, válido para qualquer ente singular nesta categoria. Kant também define a filosofia como conhecimento por conceitos, ao menos no seu aspecto escolar. Vejamos:

A filosofia é, portanto, o sistema dos conhecimentos filosóficos ou dos conhecimentos racionais por conceitos. Este é o conceito desta ciência na escola. Mas, segundo seu conceito no mundo, ela é a ciência dos fins últimos da razão humana. Este alto conceito confere dignidade à filosofia, isto é, um valor absoluto. (Kant, 2003, p. 49)

Quero, porém, contrapor a Kant uma outra noção de conceito. Porque quando Kant fala em conceito, o faz no registro do pensamento por palavras, e, portanto, o conceito não pode ser outra coisa que não representação mental da coisa percebida pelos sentidos. Como definição, o conceito é necessariamente referência. E como referência, tende ao universal, ao absoluto, ao paradigmático.

Quando Deleuze e Guattari tratam da filosofia como atividade

Educ. e Filos., Uberlândia, v. 22, n. 44, p. 55-78, jul./dez. 2008.

64 
de criação de conceitos, estão tratando do conceito não como representação mental, definição lógica, mas como uma espécie de ato de pensamento para além de qualquer palavra ou imagem. A palavra vem depois do conceito: a palavra é o que o filósofo usa para nomear um conceito, posto que ele precisa ser nomeado para poder ser comunicado. Colocando-se fora do registro do pensamento por palavras, o conceito deixa de ser referente, para tornar-se consistente. Isto é, o conceito é em si mesmo e não em relação a algo que ele representa: "

[...] não há mais projeção numa figura, mas conexão no conceito. É por isso que o conceito, ele mesmo, abandona toda referência para não reter senão conjugações e conexões que constituem sua consistência. O conceito não tem outra regra senão a da vizinhança, interna ou externa" (Deleuze e Guattari, 1992, p. 119).

A questão da vizinhança e da conectividade do conceito explicita seu caráter anti-paradigmático. Ao conceito não cabe representar, definir, o que significa paralisar o pensamento. Ao conceito compete mobilizar forças, misturar elementos, produzir experiências, pela proximidade, pela promiscuidade. Há como que uma erótica do conceito. Recorramos uma vez mais a Deleuze e Guattari:

Os conceitos são superfícies planas sem níveis, ordenadas sem hierarquia. Donde a importância das questões na filosofia: que meter num conceito, e com que co-metê-lo? Que conceito é preciso pôr ao lado deste, e que componentes em cada um? São as questões da criação de conceitos. Os pré-socráticos tratam os elementos físicos como conceitos: eles os tomam por si mesmos, independente de toda referência, e procuram somente as boas regras de vizinhança entre eles e em seus componentes eventuais. Se variam em suas respostas, é porque não compõem esses conceitos da mesma maneira, por dentro e por fora. (Deleuze e Guattari, 1992, p. 119)

Como já afirmei e não será demais repetir, se a figura é paradigmática, projetiva, hierárquica e referencial, "o conceito não é paradigmático, mas sintagmático; não é projetivo, mas conectivo; 
não é hierárquico, mas vicinal; não é referente, mas consistente" (Deleuze e Guattari, 1992, p. 119). Isto é, o conceito não produz um grande sistema de pensamento, no qual tudo caiba e através do qual tudo se explique. Ao contrário, cada conceito, embora respondendo a um determinado problema, coloca novos problemas, que pedem novas conexões, novas criações, novos conceitos. Se for possível falar em "pensamento sistemático", em "sistema de pensamento", do ponto de vista do conceito, esta possibilidade estará do lado de um "sistema dinâmico", resultante de um conjunto de conceitos que se conectam e que se reconectam, recriando o sistema a cada momento. Um sistema sem hierarquia (não há conceito "melhor" do que outro, "superior" a outro, "necessário" a outro); sem referência; sem universalidade. O conceito, definitivamente, não está no âmbito da representação.

Esta noção de conceito levou Deleuze a falar em uma espécie de pop'filosofia: "[...] não há questão alguma de dificuldade nem de compreensão: os conceitos são exatamente como sons, cores ou imagens, são intensidades que lhes convêm ou não, que passam ou não passam. Pop'filosofia. Não há nada a compreender, nada a interpretar" (Deleuze e Parnet, 1998, p. 12). Os conceitos não estão para serem compreendidos. A compreensão, o que faz, é imobilizar o pensamento, na medida em que apresenta a resposta para um problema. Se o problema está resolvido, já não é necessário pensar. Os conceitos, ao contrário, são mobilizadores e motores do pensamento, estão para fazer pensar, não para paralisar, imobilizar o pensamento. Cada conceito remete a outro conceito, a outro problema. Cada conceito conecta-se com vários outros e pede novas conexões. Assim, num movimento infinito do pensamento, o que temos é sempre novos conceitos sendo criados, por conexão, por deslizamento, por deslocamento... e a invenção de novos problemas, como num moto contínuo.

Recorro a alguns trechos de um ensaio de José Gil (2000) para reforçar esta idéia de movimento do pensamento em Deleuze:

[...] quando o pensamento se volta sobre si próprio, não interessa a Deleuze descrever a sua natureza ou a sua essência, ou descrever o

Educ. e Filos., Uberlândia, v. 22, n. 44, p. 55-78, jul./dez. 2008.

66 
seu movimento. Procura antes entrar num certo regime de pensamento ou aceder a uma certa maneira de pensar. Escrever sobre um conceito é abraçar o próprio movimento de pensamento que faz com que esse conceito seja pensável no campo da diferença. Desta forma, o pensamento é arrastado para um movimento interminável: pensamos no nosso pensamento, o que acresce esse pensamento, obrigando-nos a pensá-lo de novo e assim até ao infinito. (p.15)

O pensamento compõe-se destes múltiplos estratos que se envolvem e se deslocam com velocidades variáveis, mas ao mesmo tempo. É isto o "movimento do pensamento": uma multiplicidade de movimentos diferentes, em níveis diferentes, que desembocam uns sobre os outros num grande bloco de pensamento. (p.16-17)

Colocar um problema e resolvê-lo implica, pois, um estranho cálculo que procura menos apresentar soluções do que abrir infinitamente o campo dos problemas virtuais contidos no corpo problemático dado. (p. 22).

Esta noção do pensamento como movimento contínuo e perpétuo é a resposta de Deleuze à idéia de filosofia como conhecimento aberto, movido sempre pelo ato de questionar. Mas, ao mesmo tempo em que permanece fiel a esta tradição, o filósofo nos permite ver que a filosofia esforça-se sim por construir respostas: os conceitos. São os conceitos as resultantes do enfrentamento dos problemas pelo pensamento. Mas como os conceitos não são paradigmáticos, mas sintagmáticos, eles estão sempre abertos, estabelecendo conexões e ensejando novos problemas. Daí o movimento do pensamento.

A noção de conceito e de filosofia que Deleuze desenvolve no final dos anos 1980 (a publicação original em francês de O que é a filosofia? é de 1991) é resultante da crítica à filosofia como representação que ele desenvolveu em meados dos anos 1960, estando consolidada especialmente em Diferença e Repetição. Para ele, a tradição filosófica esteve sempre ao lado da representação, o que não permitiu que a diferença fosse pensada em si mesma. Neste contexto, o pensamento é tomado como recognição, como um 
pensar uma vez mais o já pensado. Não há, portanto, lugar para a criação. O pano de fundo, evidentemente, é o platonismo e é contra ele que Deleuze se volta, como evidencia, por exemplo, na seguinte passagem:

Descobrindo o exercício superior ou transcendente das faculdades, Platão o subordina às formas de oposição no sensível, de similitude na reminiscência, de identidade na essência, de analogia no Bem; deste modo, ele prepara o mundo da representação operando uma primeira distribuição de seus elementos, e já recobre o exercício do pensamento com uma imagem dogmática que o pressupõe e o trai. (2006, p. 207)

Eis o problema da recognição: a criação de uma "imagem dogmática do pensamento" que coloniza nossas mentes e define, de antemão, o que significa pensar. Para Deleuze, a imagem do pensamento é o pressuposto implícito e pré-filosófico de toda e qualquer filosofia: "...é sobre esta imagem que cada um sabe, que se presume que cada um saiba o que significa pensar" (idem, p. 192). Assim, nenhum pensamento é virgem, novo, mas já construído sobre pressupostos que determinam, de antemão, o que será pensado (eis aí, portanto, a recognição):

O modelo da recognição está necessariamente compreendido na imagem do pensamento. Quer se considere o Teeteto de Platão, as Meditações de Descartes, a Crítica da razão pura de Kant, é ainda este modelo que reina e que "orienta" a análise filosófica do que significa pensar /.../ Tal orientação é deplorável para a Filosofia, pois o triplo nível suposto de um pensamento naturalmente reto, de um senso comum natural de direito, de uma recognição como modelo transcendental, só pode constituir um ideal de ortodoxia. A Filosofia não tem mais qualquer meio de realizar seu projeto, que era o de romper com a doxa. (Deleuze, 2006, p. 196)

Ora, o ideal de romper com a doxa está presente na filosofia desde suas origens gregas. No entanto, o que afirma Deleuze é que na constituição de uma imagem do pensamento, sempre

Educ. e Filos., Uberlândia, v. 22, n. 44, p. 55-78, jul./dez. 2008.

68 
dogmática, o que se faz é promover uma ortodoxia, isto é, levar a doxa, que é sempre particular, para um patamar coletivo, generalizado. Impor uma imagem do pensamento significa, portanto, promover a ortodoxia, não romper com a doxa, produzindo uma filosofia crítica. Para efetivamente romper com a doxa, inaugurar um pensamento novo, genital, virgem, com o poder da crítica e da criação, é necessário que se invista na produção de um pensamento sem imagem, isto é, um pensamento fora do âmbito da recognição, em que seja possível produzir experiências de pensamento para além do já-pensado. Para Deleuze, um tal pensamento é resultado de um ato violento. Contrariamente à noção aristotélica de que o pensamento é natural no ser humano (o zoon logon echon), para o filósofo francês contemporâneo nós só pensamos quando somos forçados a pensar. Se há alguma naturalidade em pensar, ela se dá no âmbito de uma imagem dogmática do pensamento, que induz à recognição; mas, para sair desta ortodoxia, é necessária "uma violência original feita ao pensamento", uma inimizade, algo que o tire de sua "naturalidade": "o que é primeiro no pensamento é o arrombamento, a violência, é o inimigo..." (idem, p. 203).

A violência, aquilo que arromba a naturalidade de um pensamento tranqüilo e "automático" é o problema. Pensamos, efetivamente, quando nos deparamos com um problema que não tem solução no âmbito de uma imagem dogmática do pensamento. Aquilo que força a pensar, o "motor de arranque" do pensamento novo, aquilo que põe o pensamento em movimento, é o encontro, que suscita o problema. Sigamos o raciocínio de Deleuze:

Há no mundo alguma coisa que força a pensar. Este algo é objeto de um encontro fundamental e não de uma recognição. O que é encontrado pode ser Sócrates, o templo ou o demônio. Pode ser apreendido sob tonalidades afetivas diversas, admiração, amor, ódio, dor. Mas, em sua primeira característica, e sob qualquer tonalidade, ele só pode ser sentido. É assim que ele se opõe à recognição, pois o sensível, na recognição, nunca é o que só pode ser sentido, mas o que se relaciona diretamente com os sentidos num objeto que pode ser lembrado, imaginado, concebido /.../

Educ. e Filos., Uberlândia, v. 22, n. 44, p. 55-78, jul./dez. 2008 
Aquilo que só de ser sentido (o sentiendum ou o ser do sensível) sensibiliza a alma, torna-a "perplexa", isto é, força-a a colocar um problema, como se o objeto do encontro, o signo, fosse portador de problema - como se ele suscitasse problema. (2006, p. 203-204)

Para exemplar esta experiência de um pensamento virgem, genital, radicalmente novo, pois que está além de toda ortodoxia, Deleuze recorre a Artaud, que sabe que a questão não é saber orientar-se no pensamento, mas, efetivamente, pensar algo. Segundo Deleuze, Artaud sabe que "pensar é criar, não há outra criação, mas criar é, antes de tudo, engendrar 'pensar' no pensamento" (idem, p. 213). Não se trata, porém, de propor uma nova imagem do pensamento, uma imagem artaudiana ou mesmo esquizofrênica do pensamento. Isto significaria matar a força criativa. Não há método para pensar. Transformar o pensamento em método é enclausurá-lo nos limites de uma imagem do pensamento, nos limites da recognição, impedindo a força criativa.

O pensamento criativo nasce da violência do problema, constrói-se singularmente em cada experiência, para advir em algo que não fornece um panorama de respostas, mas convida ao pensamento, na medida em que mobiliza novos problemas. Ora, na obra escrita com Guattari e publicada em 1991, Deleuze definirá o resultado deste empreendimento criador como sendo o conceito. Assim, problema e conceito são as duas pontas da filosofia, de um pensamento não ortodoxo. Mas duas pontas que se unem, não no eterno retorno do círculo, mas talvez na curva torcida de um anel de Moebius, na qual não se retorna ao mesmo ponto. Problema suscita conceitos e conceito suscita problemas. Uns retornam sobre os outros produzindo novas experiências de pensamento.

Se tomamos então a filosofia como este empreendimento criativo do pensamento que, forçado por encontros que não podem ser compreendidos no âmbito do já pensado e ensejam problemas, produz conceitos sempre novos, conceitos que não estão para serem compreendidos, mas para serem experimentados e gerarem novos problemas e novos conceitos, como pensar seu exercício na sala de aula? É o que procurarei desenvolver na última parte deste artigo.

Educ. e Filos., Uberlândia, v. 22, n. 44, p. 55-78, jul./dez. 2008.

70 


\section{Filosofia e o exercício do pensamento na sala de aula}

Quando pensamos o exercício da filosofia na sala de aula, no quadro do que está sendo tratado neste artigo, a pergunta que se impõe é: estamos investindo em experiências de pensamento ou impondo uma recognição? $\mathrm{Ou}$, em outras palavras: estamos ensinando a filosofia como atitude crítica e criativa ou estamos disseminando uma imagem dogmática do pensamento? Permitame, leitor, voltar à obra de Pierre Lévy já trabalhada aqui para trazer uma última citação, importante para a argumentação que pretendo construir. Afirma ele que:

Havelock propôs uma interpretação para o nascimento da filosofia baseada na passagem de uma cultura oral para uma cultura escrita. Quando o problema da transmissão das narrativas fundadoras é resolvido, somente então pode ser colocado, em toda sua amplidão, o da fundação racional do discurso. Uma educação pela experiência, a memória, a poesia, a récita dos mitos, iria ser substituída por um ensino onde o treinamento para o exame dialético das idéias teria o papel principal. Sócrates certamente é um oralista, embora não use mais a palavra para exercícios de memória poética, mas sim como um instrumento prosaico adequado para quebrar o charme da tradição épica ou lírica, graças ao manejo de uma sintaxe e de um vocabulário conceitual estranhos à oralidade primária. (1993, p. 94, os grifos são meus).

Discordo de tal interpretação da invenção da filosofia como uma transição da cultura oral para a cultura escrita. ${ }^{7}$ Talvez possamos argumentar que o exercício da filosofia incorra na criação de um novo gênero literário; mas é inegável que, em Platão, a oralidade de Sócrates é a máquina produtora da argumentação. $\mathrm{O}$ agonismo do debate oral continua presente no texto escrito. E, mais do que a palavra escrita, é este agonismo que move o pensamento e a criação conceitual. Discordo desta interpretação porque nela fica patente a idéia de que a filosofia seja um

7 Esta é também a tese defendida por Giorgio Colli em O Nascimento da Filosofia. 
pensamento por palavras, enquanto que me ponho de acordo com a idéia de que seja a filosofia o exercício de um pensamento por conceitos que, apenas em um segundo momento, é traduzido em palavras para a comunicação, conforme já trabalhado aqui.

Mas o que quero comentar a partir da citação de Lévy é o trecho que destaquei, em que ele afirma que há neste momento da "invenção" da filosofia, coincidente com a passagem da tecnologia oral para a tecnologia escrita, uma transição de uma educação pela experiência para um ensino como treinamento. Ora, se no contexto da oralidade há uma experiência do pensamento, que se dá no âmbito da repetição (via poesia, música, rapsódia) da informação transmitida, experiência esta que permite a criação, na medida em que produz diferença, e que é o motor do aprendizado, no âmbito da escrita há um esforço de treinamento, que desmobiliza a criação, na medida em que se baseia em uma repetição que não gere diferença. $\mathrm{Ou}$, para dizer de outro modo, no âmbito da tecnologia oral temos o foco da educação posto no ato de aprender, dado pela experimentação, pela experiência própria de cada um; enquanto que no âmbito da tecnologia escrita temos o foco da educação posto no ato de ensinar, na maneira como o professor molda todo e cada aluno segundo um método, segundo uma técnica.

É inegável que, tomada como resultado a tecnologia da escrita, como pensamento por palavras, como recognição, a filosofia esforçou-se por construir imagens de pensamento, para seguir usando o conceito deleuziano. Tais imagens de pensamento podem ser e precisam ser ensinadas. Mas este ensino é um treinamento: somos treinados a pensar de determinada maneira. Ou, para dizer de outra forma: não aprendemos uma imagem do pensamento, não a experimentamos como novidade absoluta de nosso próprio pensamento, mas somos treinados para pensar segundo ela, investindo na recognição e na repetição do mesmo. Somos treinados a pensar por palavras como a possibilidade única da filosofia e o que fazemos como professores é treinar nossos alunos para fazerem o mesmo, na melhor das hipóteses (isto é, quando logramos que eles "aprendam" a filosofia).

Educ. e Filos., Uberlândia, v. 22, n. 44, p. 55-78, jul./dez. 2008.

72 
Ora, uma tal metodologia do ensino da filosofia não investe na vivência de experiências de pensamento. Como mostrou Lévy, a invenção da filosofia (ou desta filosofia comprometida mais com as palavras e menos com os conceitos em sentido deleuziano) se fez no contexto da substituição de uma "educação pela experiência" por um "ensino como treinamento". Em tal registro, ensinar filosofia significa treinar o pensamento segundo uma determinada imagem dogmática, seja ela platônica, cartesiana, kantiana ou qualquer outra.

Mas, se queremos, ao contrário, investir no exercício da filosofia como experiência do pensamento, com o trato com os conceitos, precisamos mudar o foco do ensino para o aprendizado. Isto é, deslocar o processo educativo da filosofia do "ensinar a pensar", foco serializante e generalizante que parte do professor e de seu método para atingir coletivos de estudantes, para um "aprender a pensar", em que o foco esteja no processo singular de pensamento de cada um. E, para isto, não há método.

Que significa "aprender"? Como aprender a pensar? O estudo simples de um caso concreto, "aprender a nadar", demonstra que não se trata tanto de assimilar um saber através de um método como de articular dois conjuntos de problemas para formar um único campo problemático. O mar é o primeiro campo em que as relações diferenciais entre micro-elementos constituem conjuntos constituem conjuntos e depois um sistema. O mar é uma Idéia, isto é, sistema de problemas cujas correntes e ondas são simultaneamente soluções e elementos de novos problemas. (Gil, 2000, p. 19) ${ }^{8}$

O aprendiz, afirma Deleuze em Diferença e Repetição, é aquele que coloca-se em relação com problemas, que constitui e enfrenta problemas, sejam eles práticos ou teóricos. Assim, tanto faz se falamos em aprender a nadar (ato estritamente prático) ou

8 O exemplo do aprender a nadar a que se refere José Gil é de Diferença e Repetição e na edição brasileira está desenvolvido na página 237. 
aprender a filosofar (ato estritamente teórico); em ambos os casos, trata-se de constituir um problema e enfrentá-lo, entrando no campo problemático e produzindo possibilidades de superação do problema. Acompanhemos o exemplo de Deleuze:

Aprender é penetrar no universal das relações que constituem a Idéia e nas singularidades que lhe correspondem. A idéia de mar, por exemplo, como mostrava Leibniz, é um sistema de ligações ou de relações diferenciais entre partículas e de singularidades correspondentes aos graus de variação destas relações, o conjunto do sistema encarnando-se no movimento real das ondas. Aprender a nadar é conjugar pontos notáveis de nosso corpo com os pontos singulares da Idéia objetiva para formar um campo problemático. Esta conjugação determina para nós um limiar de consciência ao nível do qual nossos atos reais se ajustam as nossas percepções das correlações reais do objeto, fornecendo, então, uma solução do problema. Mas as idéias problemáticas são ao mesmo tempo os elementos últimos da natureza e o objeto subliminar das pequenas percepções. Deste modo, "aprender" passa sempre pelo inconsciente, passa-se sempre no inconsciente, estabelecendo, entre a natureza e o espírito, o liame de uma cumplicidade profunda. (2006, p. 237)

Vemos, assim, que o aprendizado, para Deleuze, não é o mesmo que para Platão. Para este último, o aprendizado era a recognição, era a experiência de uma alma reconhecer aquilo que já sabia, mas que, pelas limitações do corpo, havia sido esquecido. Para Deleuze, ao contrário, o aprendizado é a produção de um encontro absolutamente novo, e do qual não podemos vislumbrar de antemão os resultados.

Duas observações parecem-me especialmente importantes a partir da noção de aprendizado apresentada por Deleuze: a primeira, é que se o aprendizado é um encontro com signos, uma entrada no campo problemático, cada experiência de aprendizado é singular e irrepetível. O ensino é uma espécie de convite; sua ligação com o aprendizado é frágil e tênue. Isto significa que, para além de qualquer método de ensino, não há método para o aprendizado; "não há método para encontrar tesouros nem para

Educ. e Filos., Uberlândia, v. 22, n. 44, p. 55-78, jul./dez. 2008.

74 
aprender", escreveu Deleuze (2006, p. 237). Colocar o foco do processo educativo no aprendizado significa, portanto, trabalhar a educação como experiência, como experimentação. Cada estudante precisa fazer ele próprio o movimento, ele próprio precisa experimentar o pensamento, entrar no campo problemático e experimentar o pensar por conceitos.

A segunda observação é que o que é válido para o aprendizado das atividades práticas (o nadar, por exemplo) também é válido para o aprendizado das atividades teóricas (o filosofar, por exemplo). Assim, aprender a filosofar é também, necessariamente, penetrar singularmente num campo problemático, experimentar os problemas, mobilizar-se em torno deles, experimentar conceitos, fabricar conceitos para fazer frente a tais problemas.

Assim, tratar do ensino da filosofia como criação de conceitos, como experiência do pensar por conceitos, significa fazer da sala de aula uma espécie de laboratório, ou, para escapar do referente científico, talvez seja melhor falar em uma "oficina de conceitos". Trata-se de deslocar o foco do ensino como treinamento para uma educação como experiência, em que cada estudante seja convidado a colocar seus problemas, adentrar no campo problemático e experimentar os conceitos, experimentar o pensamento por conceitos, seja manejando e deslocando conceitos criados por filósofos ao longo da história do pensamento, seja criando seus próprios conceitos. ${ }^{9}$

Algumas pistas de como agiria um professor que convida ao exercício do aprender filosofia como pensamento conceitual nos são dadas pelo próprio Deleuze, quando comenta que o ato de criar em filosofia é uma espécie de roubo, na medida em que cada filósofo entra em contato com o pensamento dos outros, mergulha

9 Tenho tentado fazer o exercício de pensar passos metodológicos para um ensino articulado com o aprendizado da filosofia como experiência com o pensamento conceitual. Ao leitor interessado sugiro a leitura de A filosofia e seu ensino: conceito e transversalidade, publicado no livro organizado por Renê J. T. Silveira e Roberto Goto, Filosofia no Ensino Médio: temas, problemas e propostas (São Paulo, Edições Loyola, 2007). 
em seus campos problemáticos e apropria-se de seus conceitos. Mas uma tal apropriação, que é o próprio aprendizado, significa uma re-criação, uma vez que os conceitos são deslocados de seu campo problemático para um outro campo, o daquele que faz a experiência do pensamento próprio. Neste sentido, o roubo é o contrário do plágio; plagiar é repetir, é fazer como, é imitar, é copiar. Roubar é repetir fazendo a diferença, é fazer como inventando um novo jeito de se fazer, é inventar de novo.

Encerro com uma última citação de Deleuze, para fique ressoando no leitor o desafio para encarnar este tipo de professor de filosofia que seja uma espécie de "motor de arranque" do ato de pensar por conceitos em cada um de seus alunos. Um professor que se coloque para além do modelo, daquele que incita a fazer como, mas também para além da figura desprezível do juiz, que julga o movimento do outro. Um professor aberto ao acaso, ao acontecimento, que faça uma longa preparação para que seja possível estar aberto e atento ao que acontece na sala de aula, permitindose seguir estes fluxos. Um professor que carregue seu "saco de utilidades", de peças e ferramentas que podem ser usadas ou desprezadas, montadas ou desmontadas, de acordo com a situação. Um professor que convite cada aluno a fazer seu próprio movimento de pensamento. Um professor que, mais do que falar bem e resolver bem os problemas, saiba como mobilizar cada estudante para colocar seus problemas e mergulhar no campo problemático, adentrando na aventura sem bússolas e sem mapas do aprender filosofia.

Professor, gostaria de conseguir dar uma aula como Dylan organiza uma canção, surpreendente produtor, mais que autor. E que comece como ele, de repente, com sua máscara de palhaço, com uma arte de cada detalhe arranjado e, no entanto, improvisado. O contrário de um plagiador, mas também o contrário de um mestre ou de um modelo. Uma preparação bem longa, mas nada de método nem de regras ou receitas. Núpcias, e não casais em conjugalidade. Ter um saco onde coloco tudo o que encontro, com a condição que me coloquem também em um saco. Achar, encontrar, roubar, ao invés de regular, reconhecer e julgar. Pois

Educ. e Filos., Uberlândia, v. 22, n. 44, p. 55-78, jul./dez. 2008.

76 
reconhecer é o contrário do encontro. Julgar é a profissão de muita gente e não é uma boa profissão, mas é também o uso que muitos fazem da escritura. Antes ser um varredor do que um juiz. Quanto mais alguém se enganou em sua vida, mais ele dá lições; nada como um stalinista para dar lições de não-stalinismo e enunciar as "novas regras". Há toda uma raça de juízes, e a história do pensamento confunde-se com a de um tribunal; ela se vale de um tribunal da Razão pura, ou então da Fé pura... Por isso muitas pessoas falam com tanta facilidade em nome e no lugar dos outros, e gostam tanto das questões, sabem colocá-las e respondê-las tão bem. (Deleuze e Parnet, 1998, p. 16-17)

\section{Referências}

COLLI, Giorgio. O Nascimento da Filosofia. Campinas: Ed. Unicamp, 1988.

DELEUZE, Gilles. Diferença e Repetição. $2^{\mathrm{a}}$ ed., Rio de Janeiro: Graal, 2006.

Ed. 34, 1992.

Gilles; GUATTARI, Félix. O que é a filosofia? Rio de Janeiro:

Gilles; PARNET, Claire. Diálogos. São Paulo: Escuta, 1998.

GALLO, Sílvio. A filosofia e seu ensino: conceito e transversalidade. In SILVEIRA, Renê J. T.; GOTO, Roberto (orgs.). Filosofia no Ensino Médio: temas, problemas e propostas. São Paulo: Loyola, 2007, p. 15-36 (coleção "Filosofar é preciso").

GIL, José. O Alfabeto do Pensamento (Prefácio à edição portuguesa de Diferença e Repetição). In DELEUZE, Gilles. Diferença e Repetição. Lisboa: Relógio D’Água, 2000 (p. 9-29).

KANT, Manual dos cursos de Lógica Geral. $2^{\mathrm{a}}$ ed. Campinas/ Uberlândia: Ed. Unicamp/Edufu, 2003. 
LÉVY, Pierre. As tecnologias da inteligência. Rio de Janeiro: Ed. 34, 1993.

Data de Registro: 27/05/08

Data de Aceite: 30/06/08

Educ. e Filos., Uberlândia, v. 22, n. 44, p. 55-78, jul./dez. 2008.

78 